\title{
Ionosphere dynamics over the Southern Hemisphere during the 31 March 2001 severe magnetic storm using multi-instrument measurement data
}

\author{
E. Yizengaw ${ }^{1}$, P. L. Dyson ${ }^{2}$, E. A. Essex ${ }^{2}$, and M. B. Moldwin ${ }^{1}$ \\ ${ }^{1}$ Institute of Geophysics and Planetary Physics, University of California, Los Angeles, Los Angeles, California, USA \\ ${ }^{2}$ CRC for Satellite System, Physics Department, La Trobe University, Bundoora, Vic 3086, Australia
}

Received: 28 September 2004 - Accepted: 15 December 2004 - Published: 30 March 2005

\begin{abstract}
The effects of the 31 March 2001 severe magnetic storm on the Southern Hemisphere ionosphere have been studied using ground-based and satellite measurements. The prime goal of this comprehensive study is to track the ionospheric response from high-to-low latitude to obtain a clear understanding of storm-time ionospheric change. The study uses a combination of ionospheric Total Electron Content (TEC) obtained from GPS signal group delay and phase advance measurements, ionosonde data, and data from satellite in-situ measurements, such as the Defense Metrological Satellite Program (DMSP), TOPographic EXplorer (TOPEX), and solar wind data from the Advanced Composition Explorer (ACE). A chain of Global Positioning System (GPS) stations near the $150^{\circ} \mathrm{E}$ meridian has been used to give comprehensive latitude coverage extending from the cusp to the equatorial region. A tomographic inversion algorithm has been applied to the GPS TEC measurements to obtain maps of the latitudinal structure of the ionospheric during this severe magnetic storm period, enabling both the spatial and temporal response of the ionosphere to be studied. Analysis of data from several of the instruments indicates that a strong density enhancement occurred at mid-latitudes at 11:00 UT on 31 March 2001 and was followed by equatorward propagating large-scale Travelling Ionospheric Disturbances (TIDs). The tomographic reconstruction revealed important features in ionospheric structure, such as quasiwave formations extending finger-like to higher altitudes. The most pronounced ionospheric effects of the storm occurred at high- and mid-latitudes, where strong positive disturbances occurred during the storm main phase, followed by a long lasting negative storm effect during the recovery phase. Relatively minor storm effects occurred in the equatorial region.
\end{abstract}

Keywords. Electromagnetics (Wave propagation) - Ionosphere (Ionospheric disturbances) - Radio science (Remote sensing)

Correspondence to: E. Yizengaw

(ekassie@igpp.ucla.edu)

\section{Introduction}

The knowledge of the electron density distribution in the Earth's ionosphere and plasmasphere is important for several purposes, such as: estimation and correction of propagation delays in the Global Positioning System (GPS); improving the accuracy of satellite navigation; predicting changes due to ionospheric storms; and predicting space weather effects on telecommunications. Communication and navigation systems that use radio signals transmitted to and from satellites are affected by the variable refractivity of the ionosphere. At the frequencies mostly used, the refractive index of the ionosphere depends inversely on the square of the transmission frequency. Therefore, considering the range of electron densities that occur in the ionosphere, the ionospheric impact can be ignored for radio signals at frequencies higher than $10 \mathrm{GHz}$. However, for L-band frequency signals used by GPS, the ionosphere may cause substantial signal delays that correspond to ranging errors of up to $60 \mathrm{~m}$. As will be explained in detail below, in the first order approximation the ranging error is proportional to the integral of the electron density along the ray path.

In addition to this propagation delay, ionospheric irregularities produce phase fluctuations that may cause a significant degradation of radio signals leading to the loss of signal lock that needs to be maintained for navigation signals (Basua et al., 1999). During severe magnetic storms, such as the one on 31 March 2001, ionospheric irregularities are enhanced in amplitude and may cause further signal degradation. Strong ionization gradients, Travelling Ionospheric Disturbances (TIDs), and phase fluctuations are often correlated with the development of geomagnetic/ionospheric storms.

Ionospheric storms represent an extreme form of "space weather", which can have significant effects on many sophisticated ground- and space-based technology systems that are very important to our way of life. These effects include electric power brownouts and blackouts due to damaging currents induced in electric power grids (e.g. Buonsanto, 1999), damage to satellites caused by high energy particles (e.g. Fuller- 
Rowell et al., 1994), increased risk of radiation exposure to humans in space and in high-altitude aircraft (e.g. Prölss et al., 1991; Prölss, 1997), changes in atmospheric drag on satellites, errors in GPS and VLF navigation systems, loss of HF communications (e.g. Klobuchar, 1991, 1996), and disruption of UHF satellite links due to scintillations (e.g. Aarons, 1982; Beach and Kintner, 1999). Under certain circumstances the economic losses from geomagnetic storms could run into hundreds of millions of US dollars (Gonzalez et al., 1999). The international network of geomagnetic observatories monitors the onset of solar-induced storms and gives warnings to military and commercial operations and other facilities that can then take action to minimize the likelihood of economic losses. However, our ability to predict ionospheric storm effects in detail is incomplete and this is one of the motivations for conducting research aimed at understanding ionospheric storm processes.

During geomagnetic storms, the disturbed solar wind compresses the Earth's magnetosphere, and intense electric fields occur that are mapped along geomagnetic field lines to the high-latitude ionosphere (Jakowski et al., 1999; Yizengaw et al., 2004). At times these penetrate to low latitudes (Aarons and Rodger, 1991). At high latitudes they produce a rapid convection of ionospheric plasma which also drives the neutral winds via collisions (Blagoveshchensky et al., 2003). At the same time, energetic particles precipitate to the lower thermosphere and below, expanding the auroral zone and increasing significantly the ionospheric ionization at higher latitudes. Intense electric currents couple the high latitude ionosphere to the magnetosphere, and the enhanced energy input causes considerable heating of the ionized and neutral gases. This leads to uneven expansion of the thermosphere producing pressure gradients which drive strong neutral winds (Buonsanto, 1999). Such disturbed thermospheric circulation changes the neutral composition and moves the plasma up and down magnetic field lines, changing the rate of production and recombination of the ionized species. At the same time the disturbed neutral winds produce polarization electric fields by a dynamo effect (Aarons and Rodger, 1991) as they collide with the plasma in the presence of the Earth's magnetic field (Blagoveshchensky et al., 2003 and the references therein). These electric fields in turn further affect the neutrals and the plasma, illustrating that the ionized and neutral species in the upper atmosphere are closely coupled.

A change of composition is an important factor in the depletion of ionization. Ground and satellite observations show that during storm periods the molecular concentration is increased and the atomic concentration is reduced, leading to the reduction of the atom to molecule ratio by a factor of about 20. Such molecularly enriched air can then be conveyed from higher to lower latitudes by the equatorward storm-induced winds (Danilov, 2001).

In this paper we examine the dynamics of the ionospheric response to a severe magnetic storm on 31 March 2001. The goal of this paper is to track the ionospheric response from high-to-low latitudes to obtain a complete picture of the se- quence and relationship of storm-time ionospheric changes. We perform tomographic reconstruction of the ionospheric density to examine the altitude and latitude dependent dynamics throughout the storm. Data from DMSP, TOPEX, $\mathrm{ACE}$, and ionosonde are used to validate the ground-based tomographic reconstruction using the ground-based GPS data.

\section{Experiment}

Geomagnetic storms generate significant irregularities in the space weather environment. The response of the Earth's ionosphere to the 31 March 2001 severe storm can be studied using many different measurement techniques, however, the GPS measured Total Electron Content (TEC) is arguably the best parameter to study the principal features of magnetic storms over extended regions of the globe (Klobuchar, 1996; Jakowski et al., 1999; Yizengaw et al., 2004).

Today, there are 29 fully operational GPS satellites, dispersed approximately uniformly around six circular orbits with a minimum of four in each, and orbiting at an altitude of about $20200 \mathrm{~km}$. The orbits, which are inclined at an angle of $55^{\circ}$ with respect to the equator, are separated from each other by a multiple of $60^{\circ}$ in right ascension $(\mathrm{Kl}-$ bouchar, 1996). Each GPS orbits the Earth with a period of $\sim 12 \mathrm{~h}$ or an angular velocity of $\omega=0.0001456 \mathrm{rad} / \mathrm{s}$ (Kunitsyn et al., 1997). Each GPS broadcasts two-spread spectrum L-band radio signals: an $L_{1}$ signal with carrier frequency $f_{1}=1.57542 \mathrm{GHz}$ and an $L_{2}$ signal with carrier frequency $f_{2}=1.2276 \mathrm{GHz}$. These two frequencies are integral multiples of a base frequency $f_{0}=1.023 \mathrm{MHz}$ (i.e. $f_{1}=1540 f_{0}$ and $f_{2}=1200 f_{0}$ ).

Due to the dispersive nature of the ionosphere, dual frequency GPS measurements can provide integral information about the ionosphere by computing the differential phases of code and carrier phase measurements. In a first order approximation this differential phase is proportional to the integrated number of free electrons along the transmission path and inversely proportional to the square of the transmission frequency. This integrated electron density, along the ray path from the satellite-to-ground, is called the slant TEC and for convenience it is usually measured in TECU ( 1 TECU $=1 \times 10^{16} \mathrm{elm}^{-2}$ ). The slant TEC is then mapped to the vertical by using a single layer approximation for the ionosphere at $h_{s p}=400 \mathrm{~km}$ height (Yizengaw et al., 2004), providing the vertical TEC, which is a more useful parameter for describing the overall ionization of the ionosphere. Data for zenith angles greater than $75^{\circ}$ are not used in this study. Methods of TEC calculation from GPS observations have been described in detail in several papers (Sardón et al., 1994; Breed et al., 1996; Horvath and Essex, 2003a,b and the references therein). More specifically, Yizengaw (2004) and Yizengaw et al. (2004) have clearly outlined the algorithm that has been used in this paper. 
Table 1. Geographic and geomagnetic coordinates of the chain of IGS stations that provided data for this study. The three letters in bracket refer to the abbreviation of the station names.

\begin{tabular}{lcccc}
\hline \multirow{2}{*}{ Stations } & \multicolumn{2}{c}{ Geographic coordinates } & \multicolumn{2}{c}{ Geomagnetic coordinates } \\
& Latitude $\left({ }^{\circ} \mathrm{N}\right)$ & Longitude $\left({ }^{\circ} \mathrm{E}\right)$ & Latitude $\left({ }^{\circ} \mathrm{N}\right)$ & Longitude $\left({ }^{\circ} \mathrm{E}\right)$ \\
\hline Guam (GUA) & 13.59 & 144.87 & 5.65 & -144.69 \\
Lae (LAE) & -6.67 & 146.99 & -15.17 & -141.05 \\
Alice (ALI) & -23.67 & 133.89 & -33.36 & -153.32 \\
Ceduna (CED) & -31.87 & 133.81 & -43.51 & -152.58 \\
Townsville (TOW) & -19.63 & 146.85 & -29.07 & -139.52 \\
Tidbinbilla (TID) & -35.38 & 148.97 & -45.72 & -133.95 \\
Hobart (HOB) & -42.81 & 147.44 & -54.12 & -133.50 \\
Macquarie Island (MAC) & -54.50 & 158.94 & -64.63 & -112.12 \\
McMurdo (MCM) & -77.84 & 166.67 & -79.93 & -33.15 \\
\hline
\end{tabular}

\subsection{Tomography}

Since Austen et al. (1986) first proposed the possibility of studying the ionosphere using satellite radio tomography, tomographic reconstruction of the ionospheric and plasmaspheric electron density has become a popular and successful means of studying the detailed features of the ionosphere and plasmasphere. Ionospheric studies using satellite radio tomography offer several advantages over traditional groundbased instruments, such as incoherent backscatter radars and ionosondes. First, tomography is inexpensive: with the exception of the transmitting satellites, the cost of all equipment (primarily receiver, antenna and computers), is small compared to the cost of an incoherent backscatter radar or ionosonde. Suitable orbiting spacecraft, such as GPS, are provided for other purposes and remove the need for the large expense of alternative spacecraft construction and launch. Second, all the equipment for a single receiving site is readily transportable, allowing the investigation of ionospheric regions to be readily extended to regions not currently covered by other methods. A third advantage of radio tomography is its wide area of coverage at a given time interval as long as there are enough receivers across the region of interest, whereas other methods (mentioned above) have a limited area of coverage as it is quite expensive to build networks to extend coverage (Mitchell et al., 1997). Furthermore, ground-based radar measurements are restricted to either the bottomside ionosphere (ionosondes) or the lower part of the topside ionosphere (usually below about $800 \mathrm{~km}$ ), so only the tomographic technique using satellites in high altitude orbits (e.g. GPS at $\sim 20200 \mathrm{~km}$ ) is capable of providing details on the structure of the entire topside ionosphere and even of the plasmasphere above.

In satellite radio tomography, now commonly referred to as Computerized Ionospheric Tomography (CIT), slant total electron content (TEC) measurements are inverted and reconstructed to obtain a two-dimensional electron density profile. In the present study tomographic reconstruction of the GPS TEC has been performed along the Australian east-

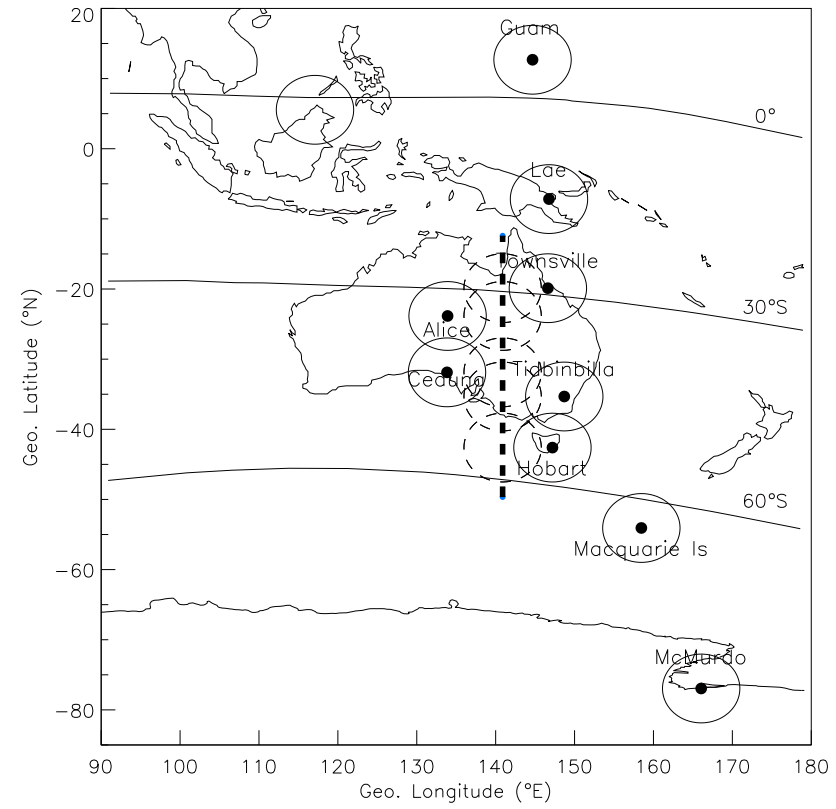

Fig. 1. Geographic maps of the seven GPS receiver stations that provided data for this study. The circles in each station depict the field of view ( $25^{\circ}$ elevation). The three horizontal curves depict the geomagnetic latitude axis at $0 \circ, 30^{\circ} \mathrm{S}$ and $60^{\circ} \mathrm{S}$, respectively, from top to bottom.

coast region using a chain of five ground-based GPS receivers. The geographic locations of the five receiving stations are given in Table 1 and Fig. 1. As depicted in Fig. 1, the geographic locations of the five stations span a range of $23.17^{\circ}$ (from $19.63^{\circ} \mathrm{S}$ to $42.80^{\circ} \mathrm{S}$ ) in latitude and all are within $9^{\circ}$ of $140^{\circ} \mathrm{E}$ longitude. The ionosphere generally varies much more rapidly with latitude than longitude, so we make the important assumption that longitudinal TEC gradients are relatively small and can be ignored. Thus, all the TEC measurements recorded at the above GPS stations are corrected (Klobuchar, 1996; Horvath and Essex, 2003a) to new tomographic-meridian sector, $140^{\circ} \mathrm{E}$ or to the location 


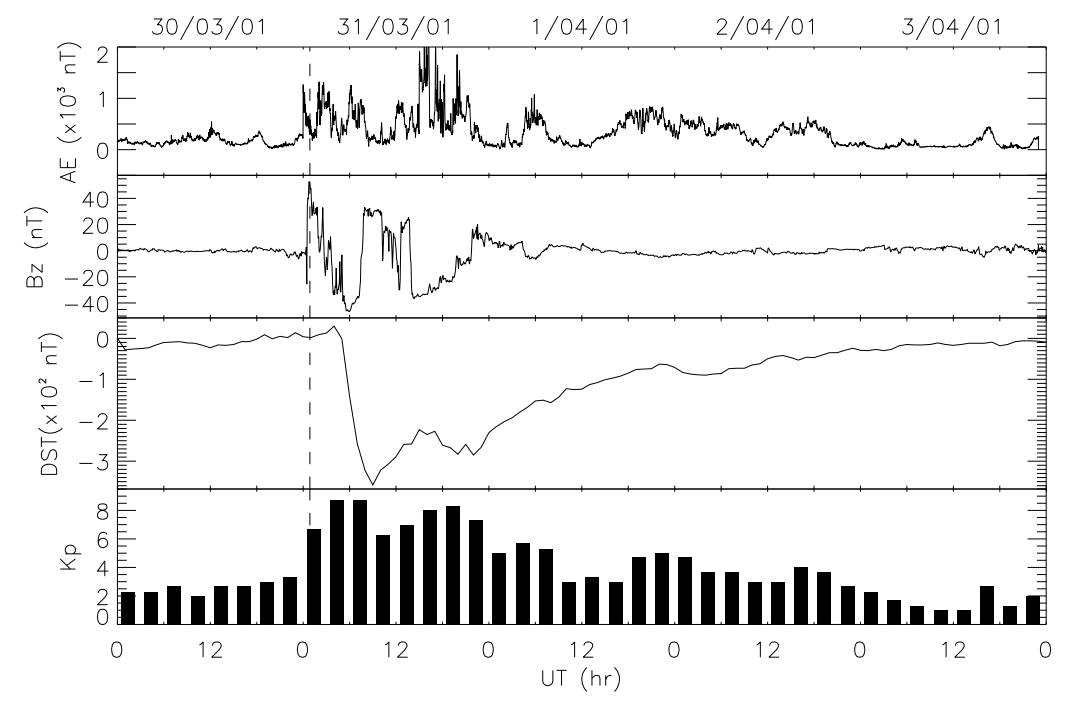

Fig. 2. Variation of geomagnetic indices: $A E$-index, IMF $B_{z}$-component, $D_{s t}$ and $K_{p}$ indices are shown from top to bottom panels, respectively. The dashed vertical line depicts the Storm Sudden Commencement (SSC) of the 31 March storm.

of the broken vertical line shown in Fig. 1. The tomographicmeridian sector is identified at the median longitudes of the stations. The broken circles centred at the vertical broken line depict the zenith cutoff of coverage at each station after they are corrected to $140^{\circ} \mathrm{E}$ meridian.

For this study we used the Algebraic Reconstruction Technique (ART) to reconstruct the GPS slant TEC into twodimensional (altitude versus latitude) density profiles. The ART algorithm, which can converge quickly in an iterative fashion compared to other reconstruction algorithms (Sutton and $\mathrm{Na}, 1996$ ) is the preferable algorithm to use for ionospheric reconstruction in a region with a limited number of widely spaced receivers, such as the GPS receiver network in the Australian region. Basically, the ART algorithm, which requires an initial guess to start with, improves the reconstruction on the initial guess with the collected experimental TEC data in an iterative fashion. The initial guess is obtained from model profiles. We used two models, IRI-2001 and Chapman profile models, to obtain the initial density profiles. The IRI-2001 model provides better bottomside profiles than other models (Bilitza, 2001). On the other hand, the Chapman profile gives a better representation of the density profile in the topside ionosphere than the IRI-2001 model. Therefore, to benefit from the strength of these two model profiles, the topside Chapman profile is attached to the subset of bottomside profiles obtained from the IRI-2001 model, to produce a new set of background profiles at intervals of $1^{\circ}$ in latitude.

\section{Observation}

Ground-based magnetometers provide the best indicator of the level of geomagnetic disturbance of the Earth's plasma environment and a variety of indices are used to describe the level of magnetic activity. The most frequently used are the
$D_{s t}, A E$, and $K_{p}$ indices, so these indices and the GSM z-component of the Interplanetary Magnetic Field (IMF) (obtained from the Advanced Composition Explorer (ACE) satellite data set), are shown in Fig. 2 for the storm period of interest. The storm sudden commencement (SSC), indicated by the vertical broken line, occurred at 00:52 UT on 31 March 2001, which is pre-noon for the $150^{\circ} \mathrm{E}$ meridian sector. On 30 March 2001 the geomagnetic disturbance was reasonably quiet with a sum of $K_{p}$-index less than 21 .

\subsection{GPS TEC}

The ground-based GPS TEC data from the cusp station McMurdo, the auroral station Macquarie Island, the mid-latitude stations Tidbinbilla and Hobart, the equatorial anomaly peak station Townsville, and equatorial stations Guam and Vanimo are studied in detail for the period of 31 March until 2 April 2001. This latitudinal chain of stations, operated by International GPS Service (IGS), is located close to the $150^{\circ} \mathrm{E}$ meridian, as shown in Fig. 1.

The ground-based GPS TEC obtained from the chain of stations, at $\sim 150^{\circ} \mathrm{E}$ geographic meridian, is shown in Fig. 3. The figure shows the diurnal behaviour of $\triangle \mathrm{TEC} \%$ for 30 March to 2 April 2001, obtained using 30-min averages of GPS data. The term $\triangle \mathrm{TEC} \%$ stands for the percentage deviation of TEC from the quiet time value (Förster and Jakowski, 2000; Yizengaw et al., 2004 and the reference therein). In our case the quiet day values are the TEC values obtained from the combination of three very quiet days, with a $K_{p}$ summed over a day value less than $8^{-}$. The three letters and the number at the right side of each panel refer to the abbreviated names of the stations and their corresponding geomagnetic latitudes. Open and solid circles on the time axis of Fig. 3 correspond to local midnight and noon, respectively. The dashed vertical line depicts the SSC time at 00:52 UT on 31 March 2001. 


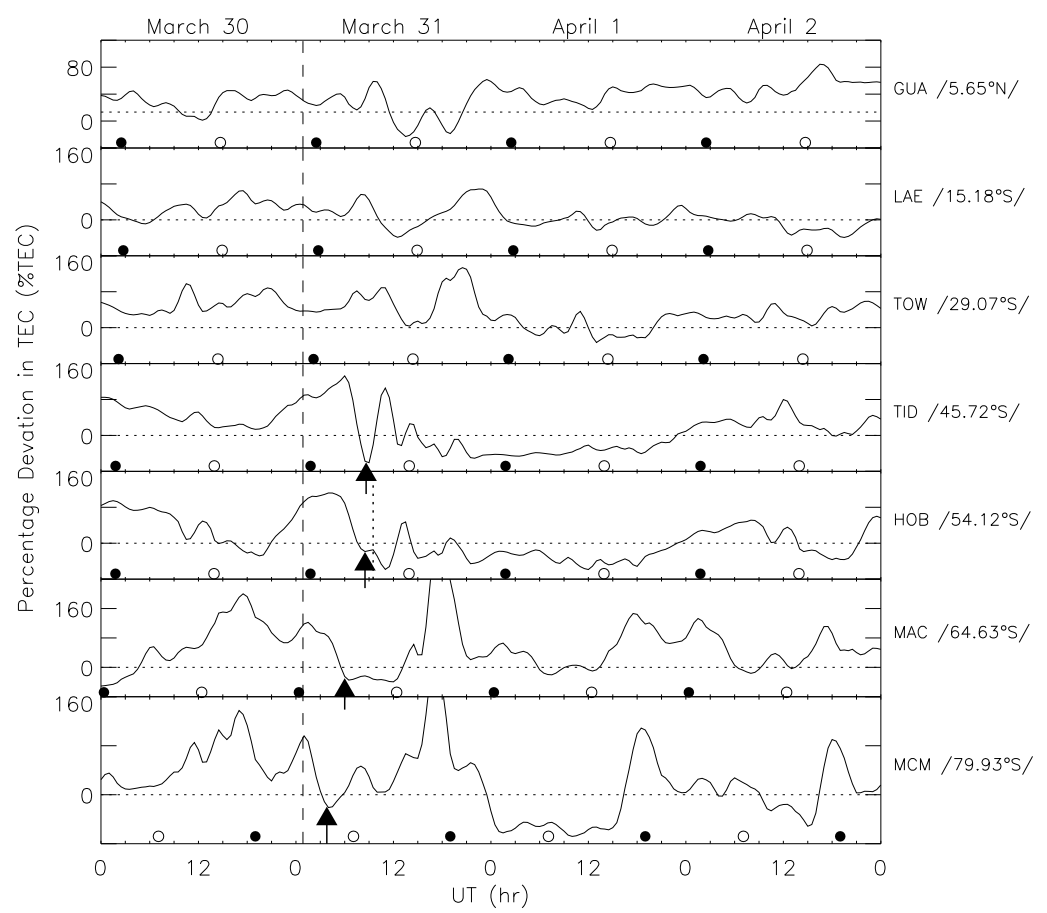

Fig. 3. Temporal profile of percentage deviation of storm-time TEC, relative to quiet days (three-day average), during 30 March to 2 April at all chains of stations. Vertical dashed line indicates SSC time. Open and solid circles on the time axis correspond to local midnight and noon, respectively.

The TEC enhancement (or positive storm effect) occurred at all stations before the SSC time on 30 March 2001. At the cusp and auroral stations, the enhancements were intensified and reached $\sim 90 \%$ and $\sim 230 \%$ in $\triangle \mathrm{TEC} \%$, respectively. At the auroral station, the enhancement decreased from $\sim 230 \%$ before the SSC time (at $\sim 15: 00$ UT on 30 March) to $\sim 130 \%$ at SSC time. Similarly, at the cusp station, the positive storm effect shows a slight decrease in $\triangle \mathrm{TEC} \%$. At mid-latitudes (Hobart and Tidbinbilla), however, the positive storm effect has been enhanced during the storm main phase. For example, at Hobart the positive storm effect increased from $\sim 0 \%$ at $\sim 3 \mathrm{~h}$ before the SSC time to $\sim 120 \%$ in $\triangle \mathrm{TEC} \%$ at SSC time. The effect remained at an intensified level for 4-6h after the time of SSC, as shown in the fourth and fifth panels from the top in Fig. 3. The positive storm effect at the lower latitude and equatorial regions decreased in intensity during the storm onset and main phase compared to the time prior to SSC (see the first top three panels in Fig. 3).

Another prominent positive storm effect that can be noted in Fig. 3 is the strong nighttime enhancement detected at the mid-latitude station, Tidbinbilla, that peaked at 11:00 UT on 31 March. This nighttime enhancement was followed by short-term TEC fluctuations (see below). These were also seen at Hobart between 12:00 and 19:30 UT and are evident in Fig. 3. Unusually strong positive effects, $>240 \%$ in $\triangle$ TEC $\%$, were detected at cusp and auroral stations on 31 March at $\sim$ 17:00 UT, which is local post midnight (see the bottom two panels in Fig. 3). Comparatively, less strong positive storm effects have been recorded at high-latitude sta- tions during the storm recovery phase, on 1 and 2 April. The positive storm effects at mid- and lower latitudes were insignificant during the storm recovery phase.

Furthermore, at the equatorial and tropical stations, substantial positive storm effects have been recorded on 31 March between 17:30 and 23:30 UT, which is the local dawn sector. Thereafter, the magnetic storm effect at these stations became insignificant, except at Guam, where a single, longlived positive storm effect, with a maximum of $\sim 110 \%$ in $\triangle \mathrm{TEC} \%$, was recorded for more than $48 \mathrm{~h}$.

Negative storm effects, i.e. ionization depletions, occurred at most stations mainly post SSC. Transient TEC depletions with a maximum depletion of $\sim 30 \%$ in $\triangle \mathrm{TEC} \%$ occurred at 04:00 UT on 31 March at McMurdo. It then extended to auroral and mid-latitude stations. The start time of the effect was tracked along the latitudinal chain of stations and is marked by upward directed arrows in Fig. 3. The negative storm effects persisted for more than $6 \mathrm{~h}$ at the auroral station. The magnitude of this long-lived negative storm effect was as much as $40 \%$ in $\triangle$ TEC\%, as shown in Figs. 3 and 4b. Figure $4 \mathrm{~b}$ presents higher time resolution (10-min average) temporal variations of $\triangle \mathrm{TEC} \%$ obtained at four of the stations on 31 March. A similar transient negative storm effect, with a depletion peak of $\sim 70 \%$ in $\triangle \mathrm{TEC} \%$ is present at 09:30 UT on 31 March in the Hobart observations. Although it is below the reference line (and therefore when there is overall a negative storm effect), the density increased slightly from the previous level at Hobart, (indicated by the dotted vertical line in Fig. 3), at about the same time as the nighttime strong 

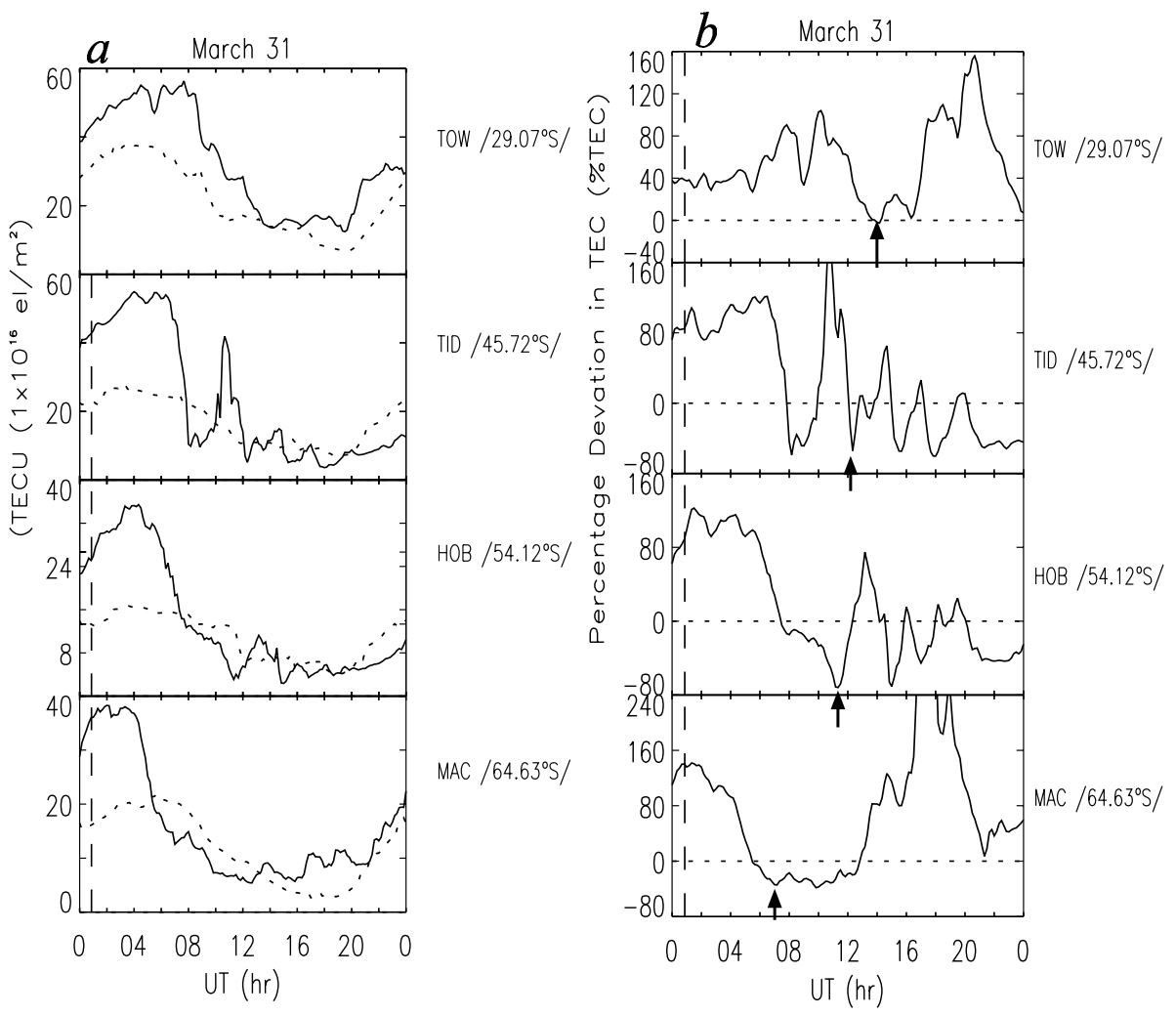

Fig. 4. TEC response for the magnetic storm on 31 March 2001. Temporal profile of GPS TEC (left) and \% $\%$ TEC (right) at different latitudes (all latitudes given are in geomagnetic coordinate system), and the vertical broken line indicates SSC (00:52 UT). The dashed line curves at the left indicate the quiet-time TEC curve.

enhancement commenced at Tidbinbilla. At the equatorial stations only transient negative storm effects were detected on 31 March at 12:00 UT at Lae and between 12:00 and 19:00 UT at Guam. An extended deep ionization depletion with a maximum depletion peak of $\sim 55 \%$ in $\triangle$ TEC\% was detected over McMurdo between 23:30 UT on 31 March and 17:00 UT on 1 April 2001. A similar long lived ionization depletion, of up to 24-h lifetime, occurred at mid-latitudes (Hobart and Tidbinbilla).

In order to study shorter time fluctuations in TEC at the mid-latitude stations, data averaged over 10-min intervals have been used and are shown in Figs. 4a and b. These figures present the 10-min average temporal variations of TEC and $\triangle \mathrm{TEC} \%$. The dashed lines in Fig. 4a represent the quiet day temporal variation of GPS TEC. Again, the broken vertical lines on both panels indicate the time of SSC. As can be seen in Figs. 4a and b, the short time TEC fluctuation effect was observed at auroral and mid-latitude stations. Slight TEC fluctuations are even observed at lower latitudes. The start time of the effect is indicated by the upward directed arrows in Fig. 4b. The magnitude of the effect increased with decreasing latitude to mid-latitudes and the maximum magnitude of the fluctuation observed at Tidbinbilla, as shown in Figs. 3 and $4 b$.

\subsection{TOPEX Altimeter TEC}

TOPographic EXplorer (TOPEX) is an oceanographic satellite designed collaboratively by the United States' NASA Jet Propulsion Laboratory (JPL) and France's Centre National d'Etudes Spatiales (CNES) to study the changing topography of the world's oceans. Since August 1992 TOPEX has been orbiting the Earth, successfully performing its mission. Travelling in a 66-deg inclination orbit at an altitude of $1336 \mathrm{~km}$, the TOPEX satellite provides about $95 \%$ of full geographic coverage of the Earth's oceans approximately every 10 days ( 9 days, $21 \mathrm{~h}, 58 \mathrm{~min}, 31.3 \mathrm{~s}$ ). An orbit, which can be described as a combination of two passes, is measured from one northbound equatorial crossing to the next. TOPEX's orbital period is about $112.42 \mathrm{~min}$ (12.8 revolutions per day). Detailed information about TOPEX can be found in Imel (1994). TOPEX uses a dual-frequency altimeter, which transmits pulses in the Ku-band $(13.8 \mathrm{GHz})$ and the $\mathrm{C}$-band $(5.6 \mathrm{GHz})$, to measure the range delay difference between the two frequencies and to compute the ionospheric range error, and thus obtains downward viewing TEC information. The TOPEX altimeter measures the vertical electron content beneath the satellite. Since the TOPEX altimeter is designed only to measure ocean heights, there are data gaps over landmasses. 
On 31 March 2001, TOPEX crossed the geographic equator at $\sim 11: 30 \mathrm{LT}$ and $\sim 23: 30 \mathrm{LT}$. The 23:30 LT track is the one that is of interest here and it is presented in Fig. 5 which gives the downward looking TOPEX altimeter TEC data on 31 March. The start and end times of the data for each individual pass are indicated on the left and right, respectively, of Figs. 5a-c. The bottom panel (Fig. 5d) presents the corresponding (as identified by colour codes) ground track of the satellite's passes. At the start of the storm recovery phase, $\sim 09: 00$ UT (see Fig. 1), TOPEX TEC recorded mid-latitude nighttime enhancements, which are labelled with "NH" in the top three panels of Fig. 5, on both the Northern and Southern Hemispheres. Another interesting feature in the figure is the differing TEC magnitudes observed for each orbit. Figure $5 \mathrm{~b}$ shows that the TEC increased towards lower latitudes, reaching a maximum of $100 \mathrm{TECU}$ at $\sim \pm 22^{\circ} \mathrm{com}-$ pared to maximum values of 70 and 50 TECU observed for the other orbits and shown in Figs. 5a and c, respectively. A clear equatorial anomaly region with approximately symmetrical anomaly peaks at $\pm 22^{\circ}$ was observed when TOPEX crossed the geographic equator at $\sim 173.62^{\circ} \mathrm{E}$ (Fig. $5 \mathrm{~b}$ and black curve in Fig. 5d). A mid-latitude trough also appeared at lower geographic latitudes on successive orbits, indicating that the trough is propagating equatorward as it is tracked by the dotted vertical line in the top three panels of Fig. 5.

\subsection{Tomograph}

Tomographic images derived from ground-based GPS TEC are shown in Fig. 6. The density distribution for the period 01:30-01:55 UT (10:00-10:25 LT) shows the normal, solar-produced increase in the background ionization as the latitude decreases (top panel). Smaller density fluctuations below $35^{\circ} \mathrm{S}$ latitude, are also evident in the dayside ionosphere shown in Fig. 6a. This may indicate the existence of TIDs during the daytime observations. The average F-layer peak density height is about $325 \mathrm{~km}$. On the other hand, the nighttime tomographic images (shown in Figs. 6a-e), for the same day, reveal density fluctuations quasi-periodic in latitude, in some cases extending, finger-like, well into the topside ionosphere.

These finger-like ionization features extend to above $1000 \mathrm{~km}$ and have a width of 300-400 km (see Figs. 6b and c). Attention should be given to the change of scales and contour intervals between the dayside ionosphere image (Fig. 6a) and the series of four nighttime ionosphere images (Figs. 6b-e). The intensity of these finger-like ionization features varies considerably with time and location. For example, the intense electron density feature that first appeared at about $41.0^{\circ} \mathrm{S}\left(53^{\circ} \mathrm{S}\right.$ geomagnetic) moved to the lower latitude of $41.0^{\circ} \mathrm{S}\left(53^{\circ} \mathrm{S}\right.$ geomagnetic) within $30 \mathrm{~min}$, as shown in Figs. 6b and c. In the fourth panel (Fig. 6d), for the 15:00-15:25 UT (00:30-00:55 LT) time period, at the initial position of the finger-like feature, there is now an ionization trough-like structure with an F2 peak density of $2.5 \times 10^{5} \mathrm{~cm}^{-3}$ at the trough minimum. (Here the term "trough" refers to a wave trough and not the mid-latitude
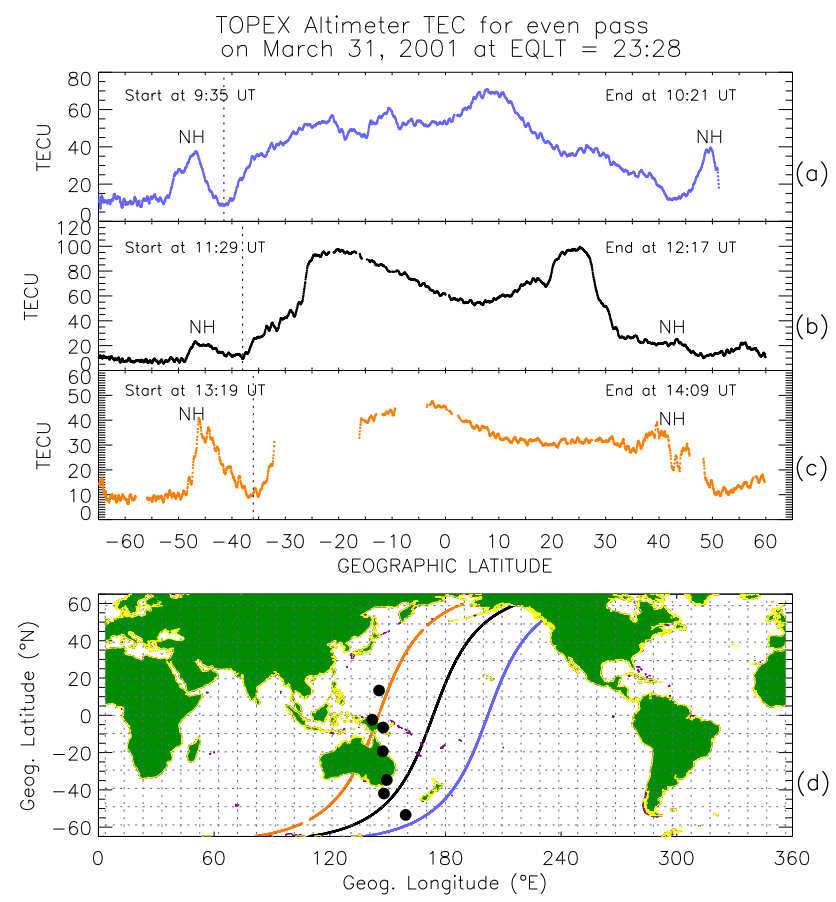

Fig. 5. (a) - (c) The TEC derived from the TOPEX altimeter, taken from an altitude of $\sim 1335 \mathrm{~km}$ near a local time of 23:30 LT. (d) The corresponding (identified by a colour code) TOPEX ground tracks.

ionospheric trough). In other words, the finger-like feature is followed by a decrease in ionization (trough) as the wavelike TID moves to lower latitude.

The number of clear electron density enhancements that occurred between the latitudes of 18 and $44^{\circ} \mathrm{S}\left(28^{\circ} \mathrm{S}\right.$ and $56.5^{\circ} \mathrm{S}$ geomagnetic) increased from three in Fig. $6 \mathrm{~b}$ (centred at 41,34 , and $29^{\circ} \mathrm{S}\left(53,45\right.$, and $40^{\circ} \mathrm{S}$ geomagnetic) to four in Fig. 6c (centred at 41, 35, 26, and $19.5^{\circ} \mathrm{S}$ ) $\left(53^{\circ} \mathrm{S}, 46.5^{\circ} \mathrm{S}, 36.5^{\circ} \mathrm{S}\right.$ and $29.5^{\circ} \mathrm{S}$ geomagnetic) latitudes) in $30 \mathrm{~min}$. The last two density enhancement peaks in the region below $26^{\circ} \mathrm{S}\left(36.5^{\circ} \mathrm{S}\right.$ geomagnetic) latitude (in Fig. 6c), which are not visible in Fig. 6b, confirm that TIDs propagated to very low latitudes during this severe magnetic storm. There is also evidence in the tomographic reconstruction image presented in Fig. 6e that this finger-like density feature migrated to even lower latitudes resulting in a comparatively narrow $(50-100 \mathrm{~km})$ finger-like structure at lower latitudes, centred on $\sim 23.5^{\circ} \mathrm{S}\left(34^{\circ} \mathrm{S}\right.$ geomagnetic). The density distribution in the vicinity of the trough-like structure, which was centred at $41.0^{\circ} \mathrm{S}$ in Fig. $6 \mathrm{~d}$, then recovered and reached a value in excess of $4.5 \times 10^{5} \mathrm{~cm}^{-3}$ in Fig. 6e. This indicates that the density distribution is returning to normal values after the period of intense magnetic activity.

\subsection{Scintillation}

For this study the GPS signal degradation or GPS phase scintillation, which represents the short-term changes in TEC over one-minute time intervals, or simply the rate of change of TEC, has been computed using the method described by 

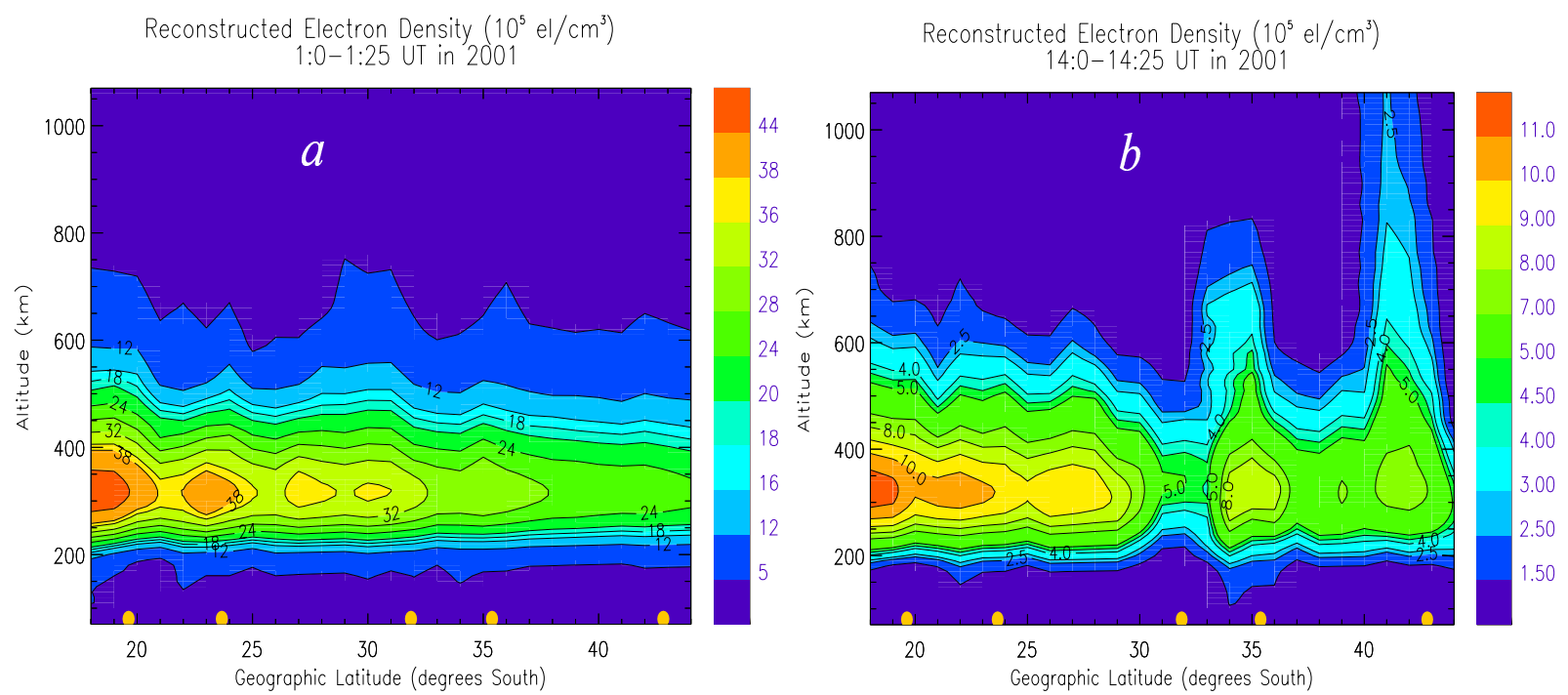

Reconstructed Electron Density $\left(10^{5} \mathrm{el} / \mathrm{cm}^{3}\right)$

14:30-14:55 UT in 2001
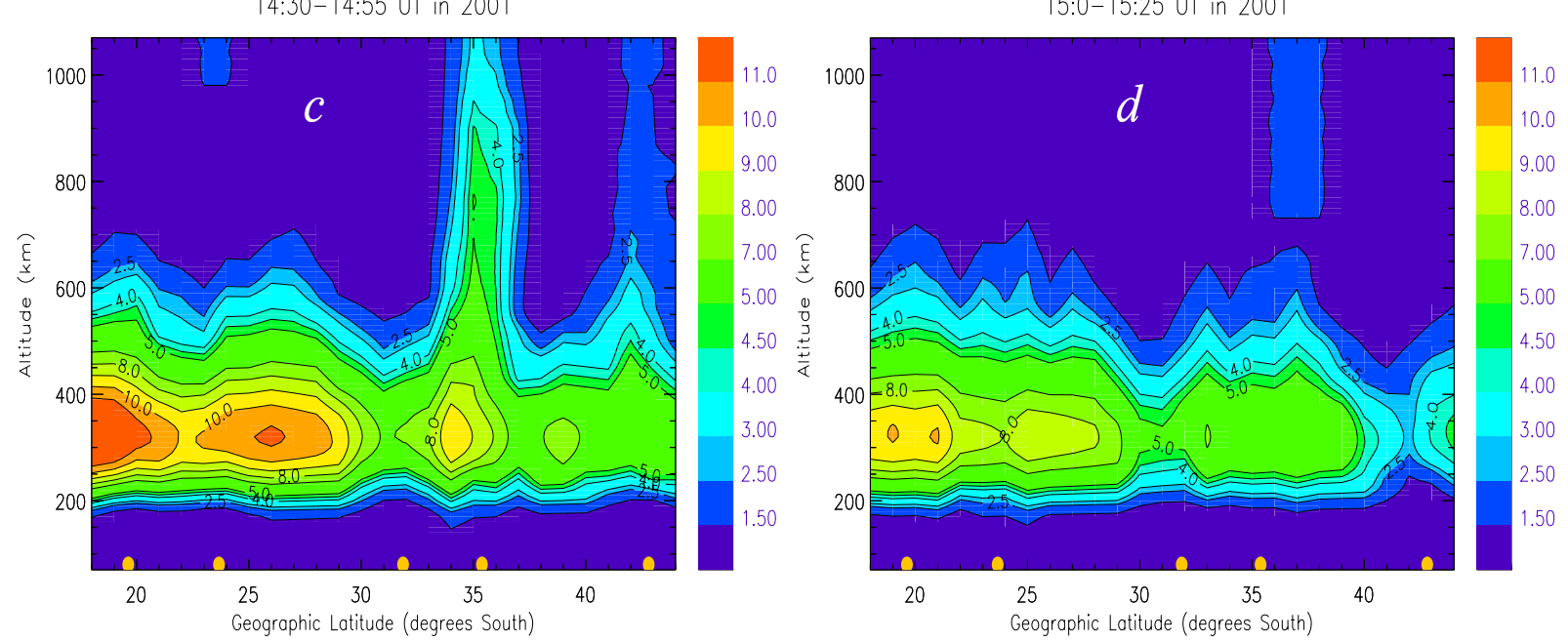

Reconstructed Electron Density $\left(10^{5} \mathrm{el} / \mathrm{cm}^{3}\right)$

15:30-15:55 UT in 2001

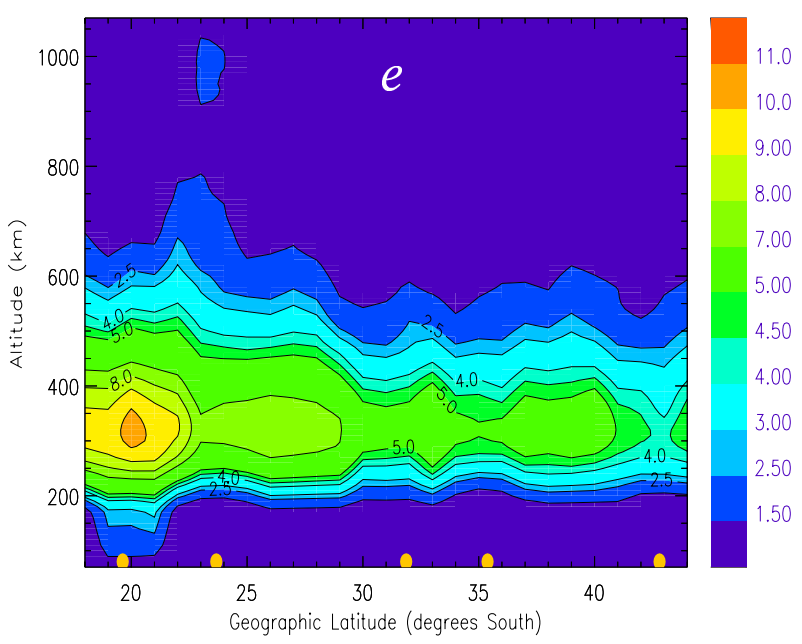

Fig. 6. Tomographic reconstructions for ground-based GPS TEC data recorded at the five stations in the Australian region on 31 March 2001. 
Warnant (1997). Figure 7 presents the rate of change of TEC computed for individual GPS satellites at Hobart and Tidbinbilla. The rate of change of TEC (dTEC) during the severe magnetic storm on 31 March 2001, shown in Fig. 7a, indicates that large values of dTEC started around 13:00 UT at Hobart, and that TEC continued fluctuating until 17:00 UT. About an hour later and thereafter, large dTEC values were observed at Tidbinbilla as well (see Fig. 7b).

\subsection{DMSP drift-meter}

Similarly, the DMSP's ion drift meter observation in Fig. 8 detected the density depletion between $\sim 23^{\circ}$ and $\sim 62^{\circ} \mathrm{S}$ geographic latitudes at the satellite height. The DMSP satellites circle the Earth in Sun-synchronous dawn-dusk orbits at $\sim 900 \mathrm{~km}$ altitude. DMSP F13 flew over the Australian east coast region at 23:10 UT when the region of depleted ionization passed through the region. The top panel shows the plasma density observed at the satellite height. The second and third panels, from the top, depict the vertical and horizontal plasma drift velocities; and the bottom panel indicates the ion and electron fluxes. The figure shows that the maximum flux intensity, $\sim 1 \times 10^{19}$ ions cm $\mathrm{cm}^{-2} \mathrm{~s}^{-1}$ or $\sim 1 \times 10^{21} \mathrm{elcm}^{-2} \mathrm{~s}^{-1}$, was driven sunward with a maximum velocity of $400 \mathrm{~m} / \mathrm{s}$ in the mid-latitude (between $42^{\circ}-56^{\circ} \mathrm{S}$ geographic) region. At the same time the density at the top panel reveals further depletion in the region, which is quite consistent with the interpretation discussed above. The figure also shows that the ion fluxes extended some $2-3^{\circ}$ equatorward of the electrons, spanning the trough region. This is the characteristic particle signature across the region of sub auroral plasma drift, whose strong convection can be responsible for the trough formation (Foster et al., 1998). Strong upward plasma velocity shown in the second panel from the top, also indicates the expansion of the topside ionosphere. Foster et al. (1998) have also observed a similar upward expansion of the topside ionosphere in the sub-auroral latitudes.

\section{Discussion}

The GPS TEC measurements from this latitudinal chain of stations show that the severe magnetic storm created both depletion and enhancement of TEC relative to quiet time (background level), i.e. both negative and positive phases of the storm, respectively. A strong nighttime enhancement followed by short-time density fluctuations is also observed at mid-latitudes. Our tomographic reconstruction observation also detected finger-like upward expansion of the ionosphere.

Several mechanisms have been considered as a probable cause of positive storm effects, which appear sometimes before the beginning of the corresponding magnetic disturbance, as we observed with a chain of stations during the 31 March 2001 severe magnetic storm. The most probable source of the effect may be related to a mechanism of penetration of the disturbance solar wind energy to ionospheric heights other than by auroral precipitation (Danilov and Las-
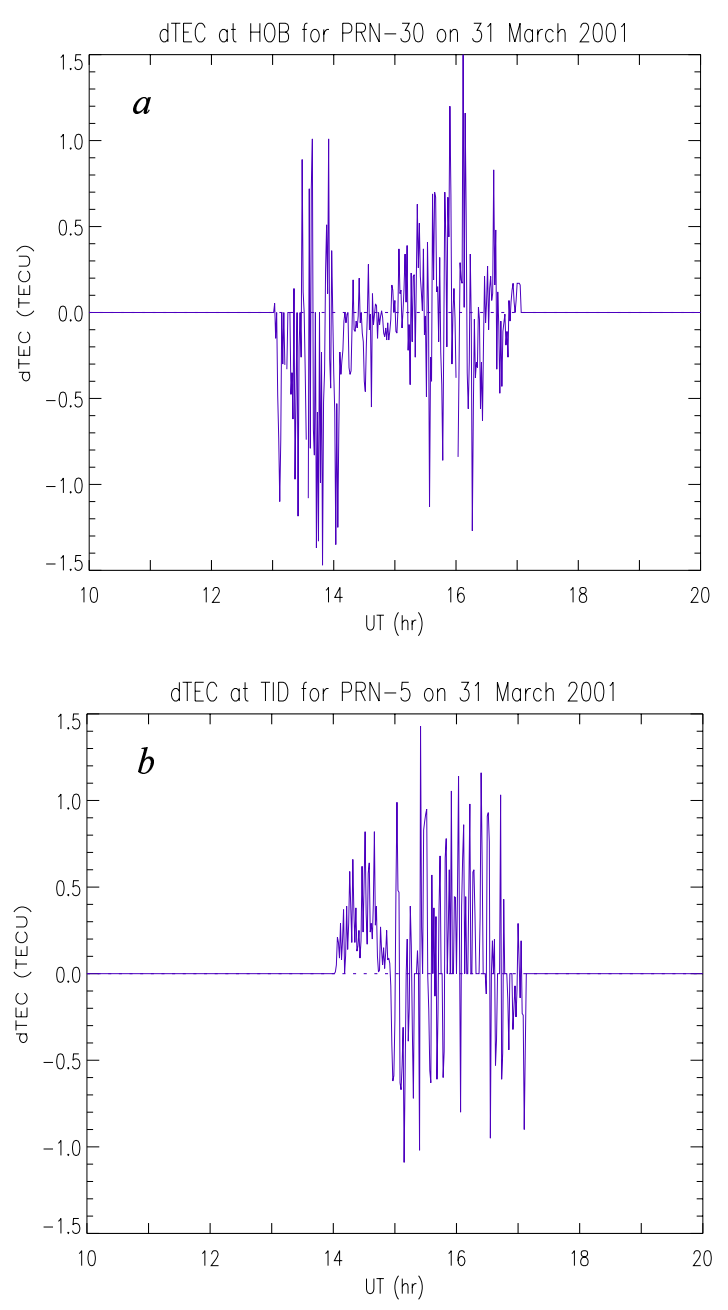

Fig. 7. The rate of change of TEC (dTEC) during three severe storm periods, demonstrating that in both cases the TIDs were migrating towards north (equatorward).

tovicka, 2001). A possibility is particle precipitation in the region of the dayside cusp, a feature that starts to respond before any geomagnetic index does to the coming geomagnetic disturbances (Kelley, 1989). The cusp then begins to expand equatorward before the beginning of the $D_{s t}$ depletion (Danilov and Lastovicka, 2001). The significant positive storm effect by (more than $\sim 90 \%$ in $\triangle$ TEC $\%$ ) observed at the chain of GPS stations on 30 March (see Fig. 3) could be the result of this effect. The energetic particle data detected by the Advanced Composition Explorer (ACE) satellite shows significant intensification (by about a factor of 100 ) at $\sim 10: 30$ UT on 29 March 2001, as indicated by the dotted line in Fig. 9. Therefore, the enhanced energetic particles may penetrate to ionospheric heights, creating ionization and thus TEC enhancement in the region. Figure 9 presents, from top to bottom, energetic ion fluxes (of energy 1050$1910 \mathrm{keV}$ ), electron fluxes (of energy $175-315 \mathrm{keV}$ ), and hydrogen fluxes (of energy $0.48-0.97 \mathrm{keV}$ ). 


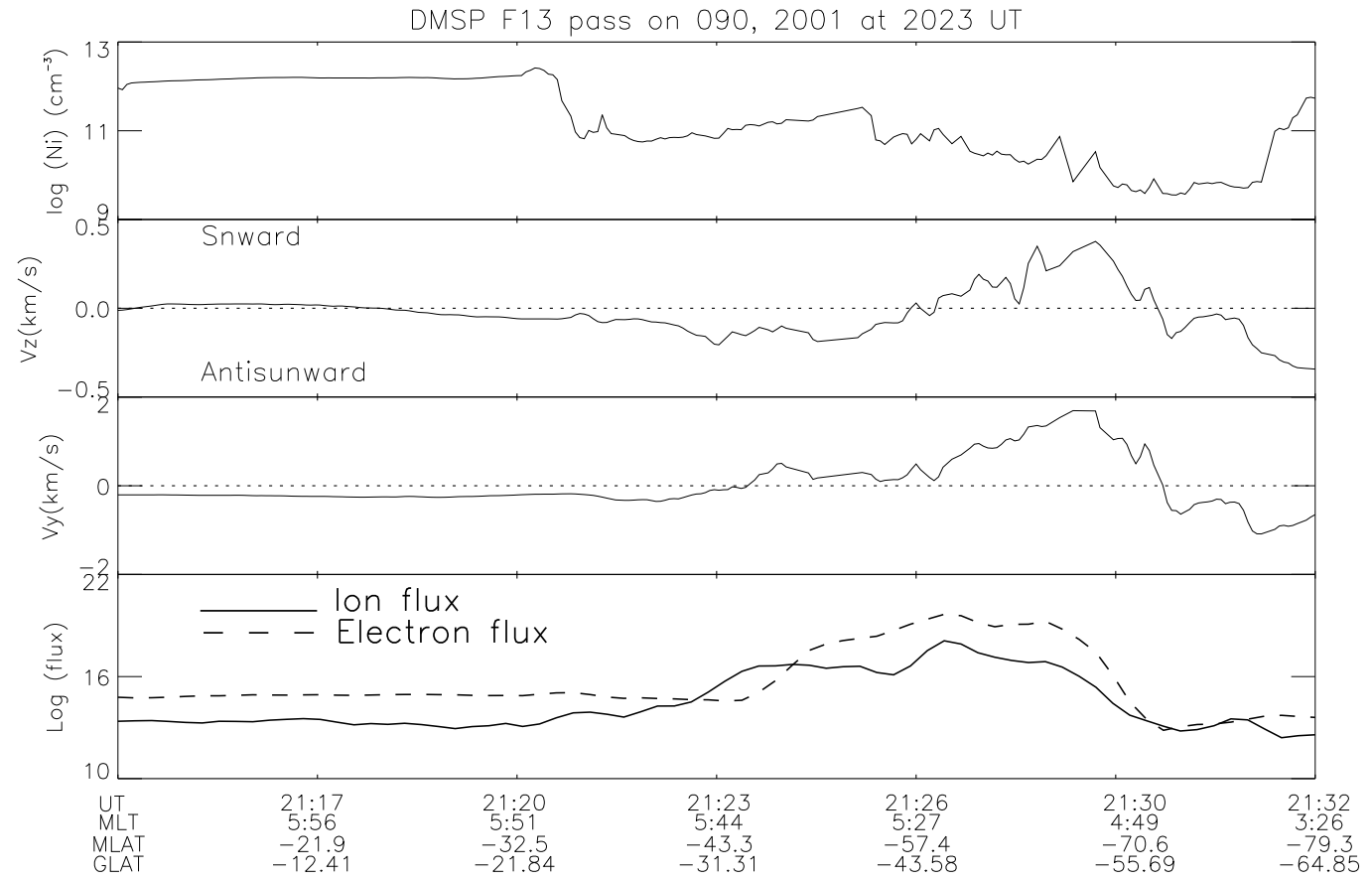

Fig. 8. The topside F-region plasma density (top), up and down (sunward and antisunward) plasma drift velocity (second from top), horizontal plasma velocity (third from top), and ions and electron flux (bottom) obtained from the DMSP 13 satellite when it cross the Australian eastcoast region.

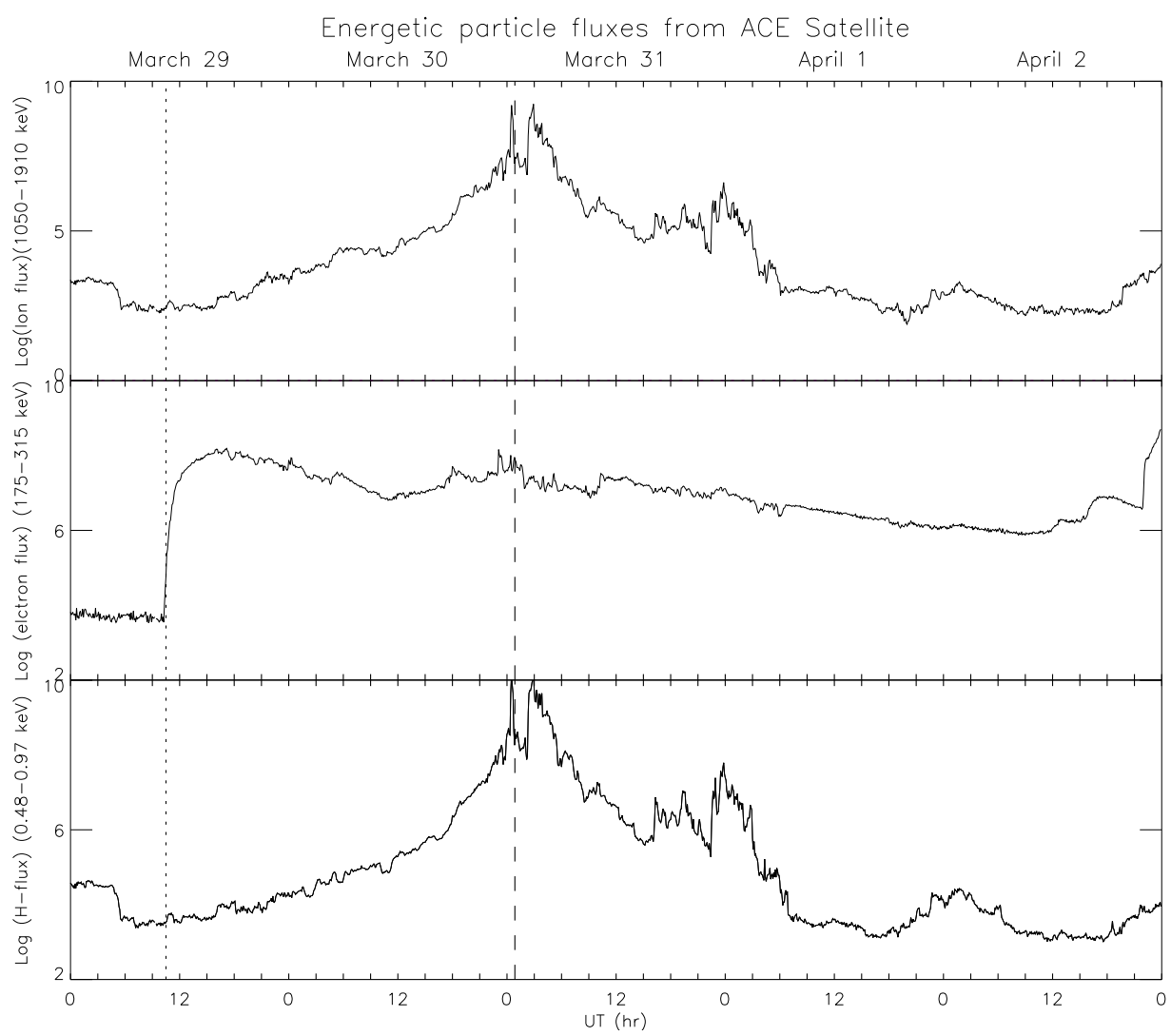

Fig. 9. The interplanetary data obtained from the ACE satellite. The ACE satellite was upstream of the Earth at a GSM position of $(x=1.4 \times$ $\left.10^{6} \mathrm{~km}, \mathrm{y}=1.2 \times 10^{5} \mathrm{~km}, \mathrm{z}=-2.0 \times 10^{5} \mathrm{~km}\right)$. From top to bottom, each panel presents the energetic ion flux, electron flux and hydrogen flux. 


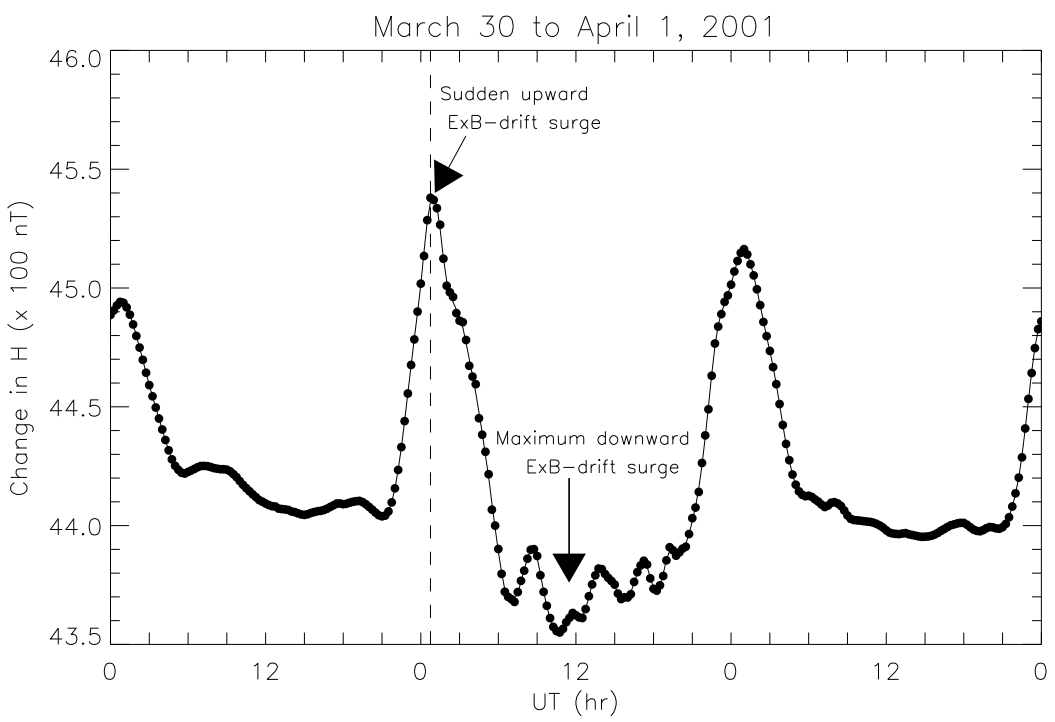

Fig. 10. The $\Delta H$ (difference between the horizontal component of the geomagnetic field $(\mathrm{H})$ at the equator and at non-equator regions) obtained from the magnetometer data at Hatizyo $\left(23.46^{\circ} \mathrm{N},-152.18^{\circ} \mathrm{E}\right.$ geomagnetic) and at Guam $\left(4.57^{\circ} \mathrm{N},-145.24^{\circ} \mathrm{E}\right.$ geomagnetic) to estimate vertical $E \times B$ drift.

The positive storm effect that occurred at the time of SSC on 31 March at all stations is clearly due to the auroral particle precipitations. The intensity of auroral energetic particles may increase by several orders of magnitude during magnetic storms and substorms. This results in an increase of electron concentration in the region which is covered by the auroral oval. The Auroral Particle and Imagery plot for this event (not shown here but can be accessed at http://sd-www.jhuapl. edu/Aurora/ovation/ovation_display.html) shows that the auroral oval expanded equatorward and totally covered Macquarie Island during the 31 March storm onset period, coinciding with a positive storm effect up to a maximum peak of $\sim 150 \%$ in $\triangle \mathrm{TEC} \%$ at SSC. The positive storm effect then expanded to the mid-latitude region, leading to the maximum peaks of $\sim 100 \%$ between 01:00 and 05:00 UT at Hobart and $\sim 120 \%$ in $\triangle \mathrm{TEC} \%$ at $\sim 06: 00$ UT over Tidbinbilla. Yizengaw et al. (2004) observed similar ionization increases at the auroral and sub-auroral regions during the severe magnetic storm on 22 September 1999. At McMurdo, however, the storm onset enhancement did not last long. It was terminated by a sharp depletion right after SSC, as shown in Fig. 3. This could be due to precipitating particles depositing very significant amounts of energy into the region, which then trigger an increase in the recombination (see below). During the period 12:00-21:30 UT the auroral imagery plot showed that the auroral oval extended equatorward, resulting in a strong positive storm effect at mid-latitude, as shown in Figs. 3 and 4b.

The large-scale enhancement of the ionospheric density at mid-latitudes on the first day of the magnetic storm is usually termed the ionospheric storm positive phase. The GPS TEC data recorded at Tidbinbilla (45.72 ${ }^{\circ} \mathrm{S}$ geomagnetic) during the 31 March severe storm reveals a large-scale ionization enhancement with a maximum peak of $\sim 160 \%$ in $\triangle$ TEC\% centred at 11:00 UT (21:00 LT) on 31 March, as shown in Figs. 3 and 4. The important source or cause of such a nighttime enhancement could be plasmasphere compression due to enhanced downward $E \times B$ drift (Foster et al., 2002; Horvath and Essex, 2003a and the references therein). The horizontal component of the geomagnetic field at the magnetic dip equator reflects the change in the equatorial plasma fountain, and the difference between $H$ at the equator and at a non-equatorial location is a good indicator of the vertical $E \times B$ drift (Horvath and Essex, 2003a). In the ionospheric dynamo, the $H$ component reflects the equatorial electrojet current (Anderson et al., 2002; Yizengaw, 2004). According to the ionospheric dynamo principle, if there is an east or westward electric field and it is perpendicular to $\mathbf{B}$, then the Hall current will be generated in the downward or upward direction, respectively. The Hall current, in turn, quickly polarizes the ionosphere and a polarization electric field will be produced. This polarization electric field is the one which is responsible for the equatorial electrojet current (Kelley, 1989). This current then produces the strong enhancement of the $H$-component magnetic field, which is observed by magnetometers located within $\pm 3^{\circ}$ of the magnetic equator. The $D_{s t}$ ring current and global Sq dynamo contribution to the $H$-component can be removed from the $H_{-}$ component field by subtracting the $H$-component recorded at a non-equator magnetometer ( $\left.H_{\text {non-equator }}\right)$ from the $H$ component value measured by a magnetometer at the magnetic equator $\left(H_{\text {equator }}\right)$. The difference is the only part of the $H$-component field that is related to the equatorial electrojet current contribution which, in turn, is directly related to the east-west electric field that triggered the system to create the electrojet current. Therefore, the $E \times B$ drift can be estimated using the resulting $\Delta H\left(\Delta H=H_{\text {equator }}-H_{\text {non-equator }}\right)$ value of the $H$-component field (Chandra and Rastogi, 1974; An- 


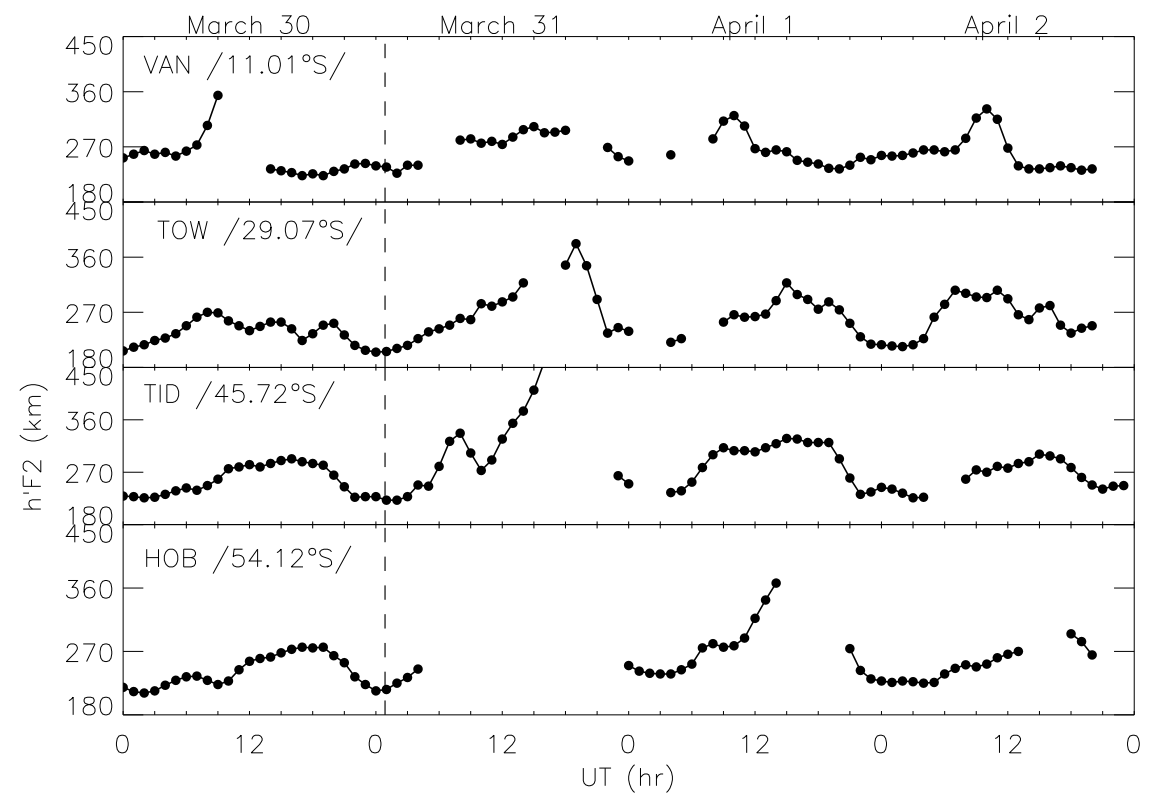

Fig. 11. One hour interval virtual $\mathrm{F}$ region height $\left(h^{\prime} F\right)$ adopted from ionsonde data recorded at the four stations (Venamo, Townsville, Tidbinbilla, and Hobart) during 30 March to 2 April.

derson et al., 2002). Figure 10 displays the parameter $\Delta H$ where Guam $\left(4.57^{\circ} \mathrm{N},-145.24^{\circ} \mathrm{E}\right.$ geomagnetic) and $\mathrm{Ha}$ tizyo $\left(23.46^{\circ} \mathrm{N},-152.18^{\circ} \mathrm{E}\right.$ geomagnetic) have been used to determine $H_{\text {equator }}$ and $H_{\text {non-equator, respectively, in the }}$ $145^{\circ}$ E longitude sector.

It can be seen from Fig. 10 that $\Delta H$ is the lowest between 10:30-11:30 UT (local nighttime in that the zonal electric field is westward) on 31 March. Therefore, this is when we can expect the maximum downward $E \times B$ drift. At the same time the TEC enhancement occurred at Tidbinbilla. Foster et al. (2002), using a number of ground- and space-based instruments, observed the storm enhanced density from GPS TEC measurement during the early evening sector. Using IMAGE EUV data, they found a highly eroded position of the plasmapause at $\sim \mathrm{L}=2$. They conclude that the 31 March storm enhanced density was an ionospheric signature of the erosion of the outer plasmasphere, which is in agreement with our interpretation mentioned above.

Similarly, the TOPEX altimeter TEC also detected nighttime mid-latitude ionization enhancements, which are labelled by "NH" in Fig. 5. The nighttime enhancements obtained from the TOPEX altimeter revealed up to a 30-TECU increase from the background level within $1-1.5^{\circ}$ latitude range. The TEC enhancement with a symmetrical equatorial anomaly shown in Fig. 5b, could be the result of the plasmasphere compression described above. At the same time when TOPEX performed the corresponding pass (black curve in Fig. 5d), the $\Delta H$ in Fig. 10 indicates maximum downward $E \times B$ drift. This suggests the TOPEX altimeter track may overlay the plasmasphere-ionosphere coupling flux tube. The behaviour of the equatorial anomaly observed in Fig. 5b and the character of mid-latitude trough in Figs. 5a-c are the subjects of another study.
The impulsive precipitating particle energy or Joule heating event at the dayside cusp region (at McMurdo) causes a sharp density depletion with a maximum depletion peak of $\sim 30 \%$ in $\triangle \mathrm{TEC} \%$ at $04: 00$ UT on 31 March, as shown in Fig. 3. Such impulsive Joule heating at the dayside cusp region gives rise to Travelling Ionospheric Disturbances (TIDs), which are much longer lived than the impulse itself and which can propagate equatorward in the form of a large-scale TID (Millward et al., 1993). Balthazor and Moffett (1997) have studied in detail the propagation of TIDs to equatorial latitudes. The equatorward propagation of such TIDs is clearly visible on GPS TEC data recorded during the severe magnetic storm on 31 March 2001 as shown in Figs. 3, 4,6 , and 7 .

The tomographic images, in Fig. 6, show that the fingerlike structures migrated to lower latitudes, which is consistent with GPS TEC observations discussed above. The finger-like structures shown in Figs. $6 \mathrm{~b}$ and $\mathrm{c}$ indicate that storm-induced features in the ionosphere extend vertically upward to higher altitude. Figure 11 presents the virtual F-layer height $\left(h^{\prime} F\right)$ obtained from ionosonde stations at Vanimo (equatorial station), Townsville, Tidbinilla, and Hobart. Although $h^{\prime} F$ is not an accurate height of the Flayer, it provides an indication of the bottom side F-layer height. The temporal plots of $h^{\prime} F$ show that the F-layer was raised to higher altitudes (beyond $450 \mathrm{~km}$ virtual height at mid-latitudes), as shown in Fig. 11, between 10:00 and 19:30 UT on 31 March, which is consistent with the fingerlike structure argument mentioned above. Unfortunately, no data were available during this time over Hobart, probably because the diffuse aurora that occurred during the time interval produced ionospheric irregularities that made the ionogram scaling difficult. 

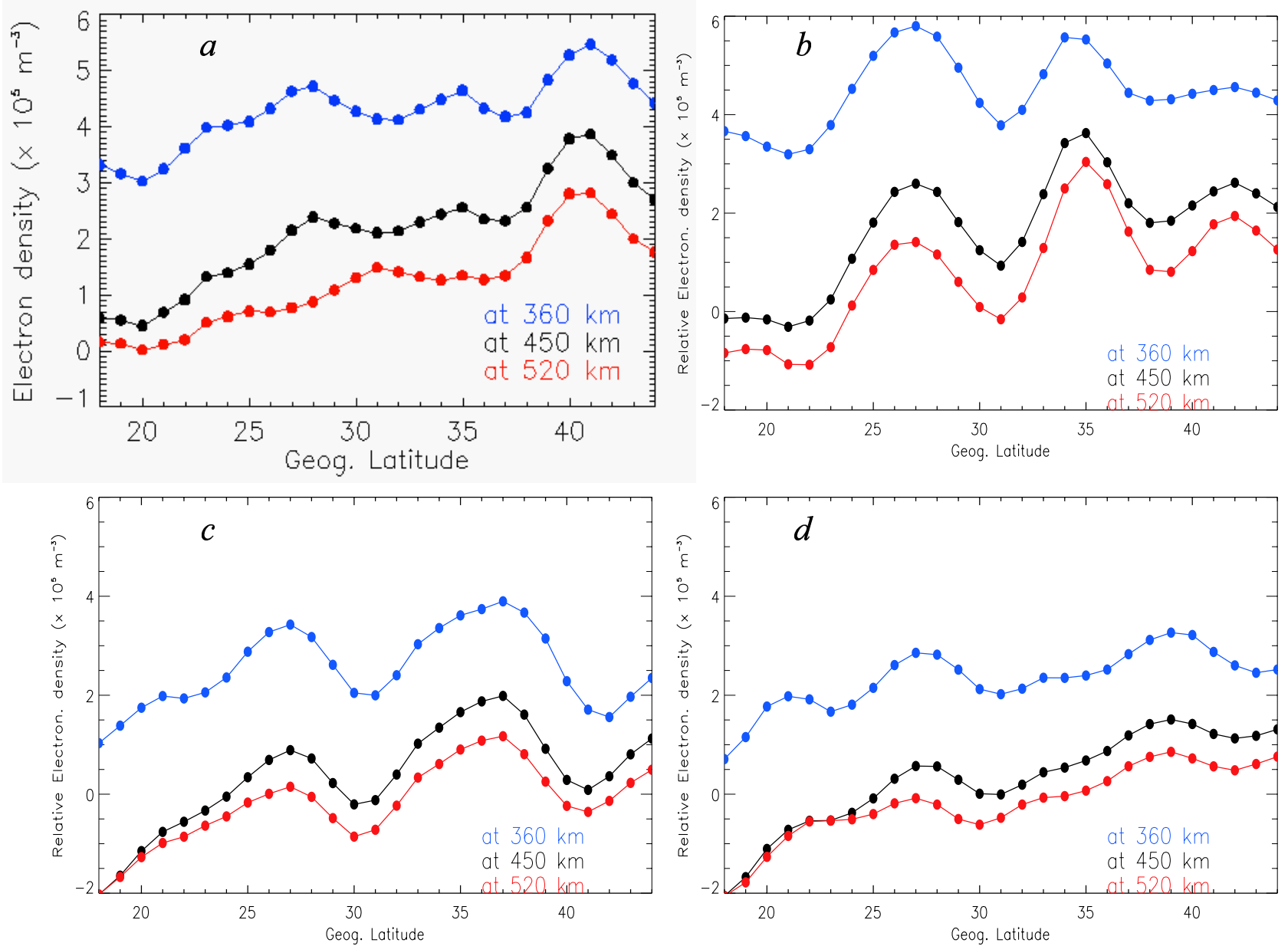

Fig. 12. Variation in the electron density of the tomographic image in Fig. 6 at three different altitudes, 360, 450, and 520 km. The background density at each height has been removed.

These finger-like structures in the ionosphere require careful analysis to establish them as real ionospheric structures and not artefacts of the algorithms used in the tomographic reconstruction. To find the parameters of the quasi-wave disturbance in the ionosphere, the latitudinal density variations in the reconstruction images at three different heights have been used. Figure 12 presents the latitudinal variations of filtered density values at three fixed altitudes in the reconstruction images. A simple filtering has been used in which the background density values of the "initial guess" ionosphere have been subtracted from the density values of the reconstruction images. This is the technique used by Pryse et al. (1995) to show TIDs effects in their ionosphere tomography observations. The blue curves in Fig. 12 show plots of the filtered density at $360 \mathrm{~km}$ height. Similarly, the black and red curves, respectively, show densities at $450 \mathrm{~km}$ and $520 \mathrm{~km}$ heights. The trough and crest positions in Fig. 12 are consistent with the two-dimensional observation of quasiwave structures at the corresponding times (Fig. 6). In addition, the troughs and crests at different altitudes occur at almost the same times, suggesting that the TIDs had almost vertical wavefronts. Cross correlation studies between the panels of Fig. 12, at different heights, also indicate that the structures moved equatorward with an average horizontal velocity of about $350 \mathrm{~m} / \mathrm{s}$. When the velocity is combined with the wavelength of $\sim 700 \mathrm{~km}$, a periodicity of about $30 \mathrm{~min}$ is obtained. Thus, the characteristics of the waves are consistent with typical values for large-scale TIDs that are a prominent feature in the nighttime ionosphere at midlatitudes (Pryse et al., 1995).

Furthermore, we used the phase signal fluctuation or rate of change of TEC, which is a good indicator of short-time TEC fluctuations, to verify the existence of TIDs in the imaging region. It is well known that the short-time TEC fluctuation of the ionosphere is caused by the passing of a perturbation-like TIDs (Kunitsyn et al., 1995; Jakowski et al., 1999). Hence, by adopting the method described by Warnant (1997), the short-term changes in TEC were computed over one-minute time intervals and presented in Fig. 7.

The rate of change of TEC (dTEC) during the severe magnetic storm on 31 March 2001, shown in Fig. 7a, shows that large values of dTEC began around 13:00 UT at Hobart, and the TEC continued fluctuating until 17:00 UT. About one hour later and thereafter, corresponding large values of 
dTEC were observed at Tidbinbilla (see Fig. 7b). These clearly indicate one main feature, an equatorward propagating quasi-wave-like disturbance, causing the fluctuations in ionospheric density.

The second dip in $D_{s t}$, which began at about 13:30 UT on 31 March (see Fig. 1), was also associated with a significant disturbance of the ionosphere. The $K_{p}$ value remained at its maximum value of $8^{+}$between 18:00 and 21:00 UT on the same day. During the period the cross-polar-cap potential drop would have increased markedly, leading to an increased input of energy at high-latitudes and expansion of the neutral atmosphere (Buonsanto, 1999; Yizengaw et al., 2004). Such a rapid expansion may then cause significant upwelling of the neutral atmosphere (i.e. the motion of air through constant pressure surfaces), causing the depletion of the atom-to-molecule ratio as air of different composition is raised to higher altitudes. This change in chemical composition causes an increased recombination in the ionosphere and a reduction in ionization concentration. Rapid heating and expansion of the atmosphere at high latitudes results in pressure gradients, which, in turn, modify the global thermospheric circulation, producing enhanced equatorward winds. The storm-induced equatorward winds, in turn, transport the composition changes to middle latitudes, again causing a reduction in the level of ionization. The TEC depletion at McMurdo (between 23:30 UT on March 31 and 15:30 UT on 1 April) and the extended depletion on 1 April over midlatitude region could be the result of these rapid heating and expansion effects. At Macquarie Island, however, only a transient negative storm effect was recorded at $\sim 07: 30$ UT on 1 April. This could be due to the auroral energetic particle precipitation producing ionization as the auroral oval moved over Macquarie Island. Idenden (1998) has also pointed out that the increase in recombination rate due to ion-neutral frictional heating, which is due to the rapid ion flows through the dayside convection throat in the cusp region (mainly during polar cap expansion), could produce significant ionization depletion in the F-region.

\section{Conclusions}

In conclusion, this study of the altitude and latitudinal ionospheric dynamics during the 31 March 2001 major geomagnetic storm using ground-based GPS tomographic reconstruction and other remote sensing and in-situ measurements provide consistent observations. The significant results of this multi-instrument study are:

- A significant high-and mid-latitude perturbation zone with dramatic enhancement of ionization, up to $230 \%$ in $\triangle \mathrm{TEC} \%$ at high-latitudes and up to $\sim 120 \%$ in $\triangle \mathrm{TEC} \%$ at mid-latitudes, has been observed.

- An extended negative storm effect (ionization depletion) was also a major consequence of the storm, especially during the storm recovery phase.
- Strong nighttime ionization enhancements at midlatitudes from plasmasphere-ionosphere coupling due to enhanced downward $E \times B$ drift, lead to strong erosion of the plasmasphere.

- Travelling atmospheric disturbances (TIDs) were detected by ground-based GPS TEC. The tomographic reconstruction revealed an interesting structure of the TIDs. It indicated equatorward propagating finger-like ionization features with $\sim 600 \mathrm{~km}$ height extension and a width of $300-400 \mathrm{~km}$. Consistent features in ionospheric density were also seen at $900 \mathrm{~km}$ altitude by the DMSP 13 ion drift meter data.

- Significant TEC scintillation at auroral and subauroral latitudes, which coincides with the passing by TIDs from a higher-latitude region.

Acknowledgements. This work has been supported partly by the La Trobe University Postgraduate Scholarship scheme, the NASA grant (grant No NNGO4GG343G), and a JPL/UCLA partnership grant. Thanks are due to the Geoscience Australia National Mapping Division (formerly Australian Surveying and Land Information Group (AUSLIG)) and IGS for the GPS data, JPL's Physical Oceanography Distributed Active Archive Centre (PO.DAAC) for TOPEX altimeter TEC data, and NOAA Satellite and information service for DMSP SSJ4 data. The ACE data are from CADWeb (http://cdaweb.gsfc.nasa.gov/cdaweb/istp_public/) and the $D_{s t}$ $A E$ and $K_{p}$ data are from WDC-2 at Kyoto (http://swdcdb.kugi. kyoto-u.ac.jp). EY and PLD are grateful to the Australian Government's Cooperative Research Centres Program for partially supporting this work

Topical Editor M. Lester thanks A. Danilov and another referee for their help in evaluating this paper.

\section{References}

Aarons, J.: Global morphology of ionospheric scintillations, Proceeding of IEEE 70, 360-378, 1982.

Aarons, J. and Rodger, A. S.: The effects of electric field and ring current energy increases on $\mathrm{F}$ layer irregularities at auroral and subauroral latitudes, Radio Sci., 26, 1115-1129, 1991.

Anderson, D., Anghel, A., Yumoto, K., Ishitsuka, M., and Kudeki, E.: Estimating daytime vertical ExB drift velocities in the equatorial F-region using ground-based magnetometer observations, Geophys. Res. Lett., 29(12), 1596, doi10.1029/2001GL014562, 2002.

Austen, J. R., Franke, S. J., and Liu, C. H.: Application of computerized tomography techniques to ionospheric research, in: Radio Beacon contributions to the study of ionization and dynamics of the ionosphere and to corrections to geodesy and technical workshop, edited by Tauriainen, A., Ouluensis Universitas, Oulu, Finland, 25-35, 1986.

Balthazor, R. L. and Moffett, R. J.: A study of atmospheric gravity waves and travelling ionospheric disturbances at equatorial latitudes, Ann. Geophys., 15, 1048-1056, 1997,

SRef-ID: 1432-0576/ag/1997-15-1048.

Basua, S., Grovesa, K. M., Quinna, J. M., and Dohertyb, P.: A comparison of TEC fluctuations and scintillations at Ascension Island, J. Atmos. S.-P., 61, 1219-1226, 1999. 
Beach, T. L. and Kintner, P. M.: Simultaneous global positioning system observations of equatorial scintillations and total electron content fluctuations, J. Geophys. Res., 104, 22 553-22 565, 1999.

Bilitza, D.: International Reference Ionosphere 2000, Radio Sci. 36, 261-275, 2001

Blagoveshchensky, D. V., Pirog, O. M., Polekh, N. M., and Chistyakova, L. V.: Mid-latitude effects of the May 15, 1997 magnetic storm, J. Atmos. Terr. Phys., 65, 203-210, 2003.

Breed, A. M: Investigation of the ionosphere over Australia using satellite transmissions, Ph. D. Thesis, School of Applied Physics, University of South Australia, 1996.

Buonsanto, M. J.: Ionospheric storms-a review, Space Sci. Rev., 88, 563-601, 1999.

Chandra, H. and Rastogi, R. G.: Geomagnetic Storm effect on ionospheric drifts and the equatorial $\mathrm{E}_{S}$ over the magnetic equator, Indian J. Radio Space Phys., 3, 332-336, 1974.

Danilov, A. D. and Lastovicka, J.: Effects of geomagnetic storms on the ionosphere and atmosphere, Int. J. Geomag. Aeronomy, 2, 209-224, 2001.

Danilov, A. D.: F2-region response to geomagnetic disturbances, J. Atmos. Terr. Phys., 63, 441-449, 2001.

Förster, M. and Jakowski, N.: Geomagnetic storm effects on the topside ionosphere and plasmasphere: a compact tutorial and new results, Surveys in Geophysics, 21, 47-87, 2000.

Foster, J. C., Cummer, S., and Inan, U.S.: Midlatitude particle and electric field effects at the onset of the November 1993 geomagnetic storm, J. Geophys. Res., 103, 26359-26366, 1998.

Foster, J. C., Erickson, P. J., Coster, A. J., Goldstein, J., and Rich, F. J.: Ionospheric signatures of plasmaspheric tails, Geophys. Res. Lett., 29(13), 10.1029/2002GL015067, 2002.

Fuller-Rowell, T. J., Codrescu, M. V., Moffett, R. J., and Quegan, S.: Response of the thermosphere and ionosphere to geomagnetic storms, J. Geophys. Res., 99, 3893-3914, 1994.

Gonzalez, W. D., Tsurutani, B. T., and Gonzalez, A. C.: Interplanetary origin of geomagnetic storms, Space Sci. Rev. 88, 529-562, 1999.

Horvath, I. and Essex, E. A.: Vertical $E \times B$ drift velocity variations and associated low- latitude ionospheric irregularities investigated with the TOPEX and GPS satellite data, Ann. Geophys., 21, 1017-1030, 2003a,

SRef-ID: 1432-0576/ag/2003-21-1017.

Horvath, I. and Essex, E. A.: The Southern-Hemisphere midlatitude day-time and nighttime trough at low-sunspot numbers, J. Atmos. Terr. Phys., 65, 917-940, 2003 b.

Idenden, D. W.: The thermospheric effects of a rapid polar cap expansion, Ann. Geophys., 16, 1380-1391, 1998,

\section{SRef-ID: 1432-0576/ag/1998-16-1380.}

Imel, D. A.: Evaluation of TOPEX/Poseidon dual frequency ionospheric correction, J. Geophys. Res., 99, 24 895-24 906, 1994.

Jakowski, N., Schluter, S., and Sardon, E.: Total electron content of the ionosphere during the geomagnetic storm on 10 January 1997, J. Atmos. Terr. Phys., 61, 299-307, 1999.
Kelley, M. C.: The Earth's Ionosphere, plasma physics and electrodynamics, International Geophysics series, V. 43, Academic Press, INC, 1989.

Klobuchar, J. A.: Ionospheric effects on GPS, GPS World, 48-51, 1991.

Klobuchar, J. A.: Ionospheric effects on GPS. In: Global Positioning System: Theory and application Vol. 1, edited by Parkinson, B. W. and Spilker, J. J., American Institute of Aeronautics and Astronautics INC, 1996.

Kunitsyn, V. E., Tereshchenko, E. D., Andreeva, E. S., Khudukon, B. Z., and Melnichenko, Y. A.: Radio tomographic investigation of ionospheric structures at auroral and middle latitudes, Ann. Geophys., 13, 1242-1253, 1995.

Kunitsyn, V. E., Andreeva, E. S., and Razinkov, O. G.: Possibilities of the near-space environment radio tomography, Radio Sci., 32, 1953-1963, 1997.

Millward, G. H., Moffett, R. J., and Quegan, S: Effects of an atmospheric gravity wave on the midlatitude ionospheric $\mathrm{F}$ layer, J. Geophys. Res., 98, 19 173-19 179, 1993.

Mitchell, C. N., Kersley, L. J., Heaton, A. T., and Pryse, S. E.: Determination of the vertical electron-density profile in ionospheric tomography: experimental results, Ann. Geophys., 15, 747-752, 1997,

SRef-ID: 1432-0576/ag/1997-15-747.

Prölss, G. W.: Magnetic storm associated perturbations of the upper atmosphere. In: Magnetic Storms, edited by Tsurutani, B T., Gonzales, W. D., Kamide, Y. and Arballo, J. K., Geophysical Monography 98, American Geophysical Union, Washington, D.C., 1997.

Prölss, G. W., Brace, L. H., Mayer, H. G., Carignan, G. R., Killeen, T. L., and Klobuchar, J. A.: Ionospheric storm effects at subauroral latitude: a case study, J. Geophys. Res., 96, 1275-1288, 1991.

Pryse, S. E., Mitchell, C. N., Heaton, J. A. T., and Kersley, L.: Travelling ionospheric disturbance imaged by tomographic techniques, Ann. Geophys., 13, 1325-1342, 1995.

Sardón, E., Rius, A., and Zarraoa, N.: Estimation of the receiver differential biases and the ionospheric total electron content from Global Positioning System observations, Radio Sci., 29, 577586, 1994.

Sutton, E. and Na, H.: Static Tomographic Reconstruction of the Time Varying Ionosphere," IEEE Signal Processing Society, IEEE Computer Society Press, 1996.

Warnant, R.: Detection of irregularities in the Total Electron Content using GPS measurements, application to a mid-latitude station, Beacon Satellite Symposium, Hungary, 1997.

Yizengaw, E.: Imaging the ionosphere, Ph. D. Tthesis, Department of Physics, School of Engineering, Faculty of Science, Technology and Engineering, La Trobe University, 2004.

Yizengaw, E., Essex, E. A., and Birsa, R.: The Southern Hemisphere and Equatorial region ionization response for September 22, 1999 severe magnetic storm, Ann. Geophys., 22, 2765-2773, 2004,

SRef-ID: 1432-0576/ag/2004-22-2765. 